\title{
Conceptualizing type 2 diabetes and its management
}

This article was published in the following Dove Press journal:

Journal of Multidisciplinary Healthcare

29 March 2016

Number of times this article has been viewed

\section{Peter Tsasis' \\ Jianhong $\mathrm{Wu}^{2}$ \\ Aijun $\mathrm{An}^{3}$ \\ Hannah J Wong' \\ Xiandong $\mathrm{An}^{3,4}$ \\ Zhen $\mathrm{Mei}^{4}$ \\ Ted Hains ${ }^{4}$ \\ 'School of Health Policy and Management, York University, Toronto, ON, Canada; ${ }^{2}$ Centre for Disease Modelling, York University, Toronto, ON, Canada; ${ }^{3}$ Department of Electrical Engineering of Computer Science, York University, Toronto, ON, Canada; ${ }^{4}$ Manifold Data Mining Inc., Toronto, ON, Canada}

Correspondence: Peter Tsasis York University, 4700 Keele St, HNES42I Toronto, ON M3JIP3, Canada Email tsasis@yorku.ca

\begin{abstract}
Type 2 diabetes is growing worldwide due to population growth, increased rates of obesity, unhealthy diet, and physical inactivity. Risk assessment methods can effectively evaluate the risk of diabetes, and a healthy lifestyle can significantly reduce risk or prevent complications of type 2 diabetes. However, risk assessment alone has not significantly improved poor adherence to recommended medical interventions and lifestyle changes. This paper focuses on the challenge of nonadherence and posits that improving adherence requires tailoring interventions that explicitly consider the social determinants of health.

Keywords: type 2 diabetes, nonadherence, tailored interventions, data mining and cluster analysis
\end{abstract}

\section{Introduction}

Type 2 diabetes is becoming a global pandemic. Recent estimates from the International Diabetes Federation suggests that $8.3 \%$ of the world's population between the ages of 20 and 79 have type 2 diabetes and that by 2035 this will increase to $10.1 \%{ }^{1}$ The global burden of type 2 diabetes is especially concerning - it is the eighth leading cause of death in the world ${ }^{2}$ and its associated costs are estimated to exceed $\$ 548$ billion annually or $11.0 \%$ of world health spending. ${ }^{1}$ Significant complications associated with type 2 diabetes, including kidney failure, stroke, heart disease, and blindness, further add to the burden of the disease.

The increasing incidence and prevalence of type 2 diabetes is influenced by an aging population and increased life expectancy, but more largely attributed to modifiable risk factors including rising obesity rates, ${ }^{3}$ unhealthy diets, ${ }^{4}$ low physical activity, ${ }^{5}$ and smoking. ${ }^{6}$ Nonmodifiable risk factors, in particular race/ethnicity, are also associated with type 2 diabetes. ${ }^{7,8}$ Multiple lines of evidence suggest that modest changes in modifiable risk factor levels can improve type 2 diabetes outcomes. In a recent review of lifestyle, pharmacological and surgical therapies targeted at preventing and managing type 2 diabetes, Khavandi et al ${ }^{9}$ reported on a number of studies where modest weight loss (eg, losing $4 \mathrm{~kg}$ over 3-6 years) showed prevention or significant delays in onset of type 2 diabetes in high-risk populations. However, the ability to adapt and adhere to healthy behaviors and lifestyle changes that reduce risk and better manage type 2 diabetes has proven to be especially challenging.

In this paper, we focus on the particularly challenging issue of nonadherence to recommended medical management of type 2 diabetes. We posit that improving adherence requires tailored interventions that explicitly consider the social determinants of health. Finally, we describe how big data, data mining, and cluster analysis can serve as the foundation for tailored adherence interventions. 


\section{Type 2 diabetes management and the issue of nonadherence}

Management of type 2 diabetes concentrates on keeping blood sugar levels as close to normal range as possible and includes key elements of 1) diabetes education, 2) exercise and weight management, 3) nutrition, 4) medication adherence, 5) stress and lifestyle management, and 6) blood pressure regulation. Patients with type 2 diabetes, like those with many chronic conditions, are their own primary caregivers, and successful management of the disease relies largely on the decisions patients themselves make about their behavior and lifestyle. ${ }^{10}$

People with type 2 diabetes can expect to enjoy independent and active lives if they make a lifelong commitment to diabetes self-management. Despite this compelling justification, nonadherence to health care provider recommendations is of great concern. Estimates of nonadherence in the type 2 diabetes population range from $50 \%{ }^{11}$ to as high as $93 \%{ }^{12}$ The consequences of nonadherence are significant - type 2 diabetes patients who did not adhere to management recommendations had almost twice the annual health care costs of patients with higher levels of adherence. ${ }^{13}$

Many recent interventions aimed at improving adherence have taken advantage of web-based technologies. Interventions include interactive websites and social media to encourage and maintain lifestyle modifications like exercising and healthy eating, ${ }^{14,15}$ real-time feedback on blood glucose levels and other performance indicators, ${ }^{16,17}$ mobile phone applications that connect personal coaches and other care providers with patients, ${ }^{18,19}$ and text message reminders aimed at improving medication adherence. ${ }^{20}$ These interventions have a common goal of increasing information, ownership, support, and peer connectedness to the type 2 diabetes population. Interventions have shown for the most part positive, albeit not always significant, results in improving adherence and patient outcomes. We posit that interventions would be more effective and their findings more conclusive if social determinants of health were explicitly incorporated in intervention design and implementation.

\section{Social determinants of health influence health behaviors like adherence}

There is growing evidence to support the notion that to fundamentally improve type 2 diabetes adherence behavior, management practices and interventions need to incorporate the social determinants of health as core components of their strategies.
Social determinants of health include any nonmedical factors influencing health, including the social and economic environment, the physical environment, and the person's individual characteristics and behaviors. ${ }^{21}$ The association between social determinants including income, stress, work conditions, social support, values and beliefs on health status, and outcomes has been well documented. In particular, individuals who are socioeconomically challenged have increased risk of developing type 2 diabetes, ${ }^{22}$ poorer diabetes self-management, ${ }^{23}$ and worse health outcomes. ${ }^{24}$ For example, Waqar et al ${ }^{25}$ found an association between socioeconomic deprivation and nonattendance to a diabetic retinopathy screening program. Additionally, in a study of Hispanic and non-Hispanic white type 2 diabetes patients, Walsh et $\mathrm{al}^{26}$ found that a composite variable, representing patient adaptation or ability to cope with one's own illness, accounted for more variation in adherence, quality of life, clinical outcomes, and service utilization than did ethnicity, which often serves merely as a proxy for patient values and beliefs.

These studies highlight that while professionals are experts about diseases and the recommended course of action, patients are experts about their own lives. As such, their beliefs and values, knowledge and skills, and social and economic situation can heavily influence their decision to adhere to recommendations or not. Notwithstanding the compelling evidence, currently there exists few adherence interventions that recognize and explicitly integrate the broad range of important social determinants of health into their strategies for type 2 diabetes or, for that matter, other chronic conditions. This may reflect limitations with data availability, the dynamic complexity of social determinants and health behavior, or the lack of innovative approaches to analyze and uncover meaningful patterns and relationships that can be used to tailor adherence interventions.

\section{How big data, data mining, and cluster analysis can be used to improve adherence}

We propose the use of big data about consumer lifestyle and social determinants of health, combined with advanced data mining technologies and innovative cluster analysis techniques, to segment the type 2 diabetes population into meaningfully distinct adherence behavior clusters that will respond differently to varied management approaches. We believe that tailored communications to distinct behavioral clusters is the foundation for efforts aimed at improving self-management adherence of type 2 diabetes and other chronic conditions. 
While the use of big data - massive amounts of structured and unstructured data that can be captured and analyzed - and data mining and cluster analysis techniques have been used successfully by many industries for targeted communication, health care has lagged behind in such efforts. However, there is growing evidence of its use to target health promotion efforts and personalize medicine. ${ }^{27-29}$ Additionally, cluster analysis has been used to help identify irritable bowel syndrome (IBS) patients at higher risks for ineffective communication and nonadherence to medication. ${ }^{30}$ In another study, IBS patients were clustered according to physiological, physical, and psychological parameters. Three markedly different clusters were generated and authors reported that inclusion of psychosocial factors in the analysis enabled more clinically meaningful groups to be identified than those traditionally identified using clinical parameters. ${ }^{31}$ In a study of hypertensive patients, researchers analyzed the relationship between the attitudes and self-reported behavior of patients and found six distinct patient segments (proactive, confident, concerned, confused, resigned, and skeptical) that can be used in tailored interventions. ${ }^{32}$

Successfully employing big data, data mining and cluster analysis requires 1) access to rich databases that include at minimum national demographic, geographic, household spending, and community health survey data, 2) innovative techniques to fuse these diverse data sources and transform the big data into relatively homogeneous clusters with powerful predictors, and 3 ) rigorous refinement and validation of clusters, including choosing the optimal number of clusters, measuring stability of the clusters, and studying the longitudinal trends for clustered data.

\section{Conclusion}

There is a need to leverage health care related big data, stateof-the-art data mining technologies, and cluster analysis techniques so that social determinants of health - key drivers of adherence - can be explicitly incorporated in the design and implementation of interventions to improve selfmanagement of type 2 diabetes. Via tailored communications distinct to behavioral clusters, we strongly believe there is true potential to improve care and health outcomes of patients with type 2 diabetes.

We also believe this brings a new way of thinking, acting, and organizing practice. Operationalizing interventions for chronic diseases such as diabetes requires establishing patient ownership through behaviors that denote cognitive participation, shared knowledge and meaning, and the belief in the value of the intervention within the patient's lifestyle and personal preference. ${ }^{11}$ As a result, health care interventions need to take a more holistic approach, giving emphasis to the social norms and support connections in which the interventions are enacted.

Focusing on the patient-centered nature of the intervention in addressing behavioral, emotional, situational, and cognitive barriers may be a more effective way of making treatment and behavior adherence recommendations. In our efforts to move in this direction, we are using a data-driven algorithm that interlinks patient data on physical activity, mental attitudes, health behavior, diet patterns, lifestyle, social network connections, and economic, demographic, and geographic data. By identifying clusters of patients, we can engage patients with customized coaching strategies to minimize risk factors, giving emphasis to the conditions (attitudes and beliefs, mental state, and perceived stress) and social norms (community connections and family supports) in which the intervention is enacted. We can monitor change over time by measuring the health behavior change process components identified in the interventions for each cluster of patients.

Future research is needed to provide structured guidelines for health professionals to use at any point in the patient consultation process within the cluster groupings of the intervention. This will require changes in the way we use patientlevel data in primary health care delivery and in the way health care professionals deliver health care. By focusing on understanding patient attributes, clustering patients in distinct patterns of health behavior, health perceptions and social supports, and tailoring interventions to those patterns, we can achieve improved health outcomes for patients with type 2 diabetes.

\section{Disclosure}

The authors report no conflicts of interest in this work.

\section{References}

1. International Diabetes Federation. IDF Diabetes Atlas. 6th ed. Brussels, Belgium: International Diabetes Federation; 2013.

2. World Health Organization. Fact Sheet N 310: The Top Ten Causes of Death. Geneva, Switzerland: World Health Organization; 2014.

3. Golay A, Ybarra J. Link between obesity and type 2 diabetes. Best Pract Res Clin Endocrinol Metab. 2005;19(4):649-663.

4. Khazrai YM, Defeudis G, Pozzilli P. Effect of diet on type 2 diabetes mellitus: a review. Diabetes Metab Res Rev. 2014;30 (Suppl 1):24-33.

5. Colberg SR, Sigal RJ, Fernhall B, et al. Exercise and type 2 diabetes: the American College of Sports Medicine and the American Diabetes Association: joint position statement executive summary. Diabetes Care. 2010;33(12):2692-2696.

6. Spijkerman AM, van der AD, Nilsson PM, et al. Smoking and long-term risk of type 2 diabetes: the EPIC-InterAct study in European populations. Diabetes Care. 2014;37(12):3164-3171. 
7. Abate N, Chandalia M. The impact of ethnicity on type 2 diabetes. J Diabetes Complications. 2003;17(1):39-58.

8. Campbell JA, Walker RJ, Smalls BL, Egede LE. Glucose control in diabetes: the impact of racial differences on monitoring and outcomes. Endocrine. 2012;42(3):471-482.

9. Khavandi K, Amer H, Ibrahim B, Brownrigg J. Strategies for preventing type 2 diabetes: an update for clinicians. Ther Adv Chronic Dis. 2013;4(5):242-261.

10. Bodenheimer T, Lorig K, Holman H, Grumbach K. Patient self-management of chronic disease in primary care. JAMA. 2002;288(19):2469-2475.

11. Haynes RB, McDonald H, Garg AX, Montague P. Interventions for helping patients to follow prescriptions for medications. Cochrane Database Syst Rev. 2002;2:CD000011.

12. Cramer JA. A systematic review of adherence with medications for diabetes. Diabetes Care. 2004;27(5):1218-1224.

13. Sokol MC, McGuigan KA, Verbrugge RR, Epstein RS. Impact of medication adherence on hospitalization risk and healthcare cost. Med Care. 2005;43(6):521-530.

14. Connelly J, Kirk A, Masthoff J, MacRury S. The use of technology to promote physical activity in Type 2 diabetes management: a systematic review. Diabet Med. 2013;30(12):1420-1432.

15. Cotter AP, Durant N, Agne AA, Cherrington AL. Internet interventions to support lifestyle modification for diabetes management: a systematic review of the evidence. J Diabetes Complications. 2014;28(2):243-251.

16. Tang TS, Digby EM, Wright AM, et al. Real-time continuous glucose monitoring versus internet-based blood glucose monitoring in adults with type 2 diabetes: a study of treatment satisfaction. Diabetes Res Clin Pract. 2014;106(3):481-486.

17. Hunt CW. Technology and diabetes self-management: an integrative review. World J Diabetes. 2015;6(2):225-233.

18. Goyal S, Cafazzo JA. Mobile phone health apps for diabetes management: current evidence and future developments. QJM. 2013;106(12):1067-1069.

19. Toma T, Athanasiou T, Harling L, Darzi A, Ashrafian H. Online social networking services in the management of patients with diabetes mellitus: systematic review and meta-analysis of randomised controlled trials. Diabetes Res Clin Pract. 2014;106(2):200-211.
20. Vervloet M, van Dijk L, Santen-Reestman J, et al. SMS reminders improve adherence to oral medication in type 2 diabetes patients who are real time electronically monitored. Int J Med Inform. 2012;81(9):594-604.

21. World Health Organization. The Economics of the Social Determinants of Health and Health Inequalities: A Resource Book. Geneva, Switzerland: World Health Organization; 2013.

22. Agardh E, Allebeck P, Hallqvist J, Moradi T, Sidorchuk A. Type 2 diabetes incidence and socio-economic position: a systematic review and meta-analysis. Int J Epidemiol. 2011;40(3):804-818.

23. Clark ML, Utz SW. Social determinants of type 2 diabetes and health in the United States. World J Diabetes. 2014;5(3):296-304.

24. Walker RJ, Smalls BL, Campbell JA, Strom Williams JL, Egede LE. Impact of social determinants of health on outcomes for type 2 diabetes: a systematic review. Endocrine. 2014;47(1):29-48.

25. Waqar S, Bullen G, Chant S, Salman R, Vaidya B, Ling R. Cost implications, deprivation and geodemographic segmentation analysis of non-attenders (DNA) in an established diabetic retinopathy screening programme. Diabetes Metab Syndr. 2012;6(4):199-202.

26. Walsh ME, Katz MA, Sechrest L. Unpacking cultural factors in adaptation to type 2 diabetes mellitus. Med Care. 2002;40 (1 Suppl):I129-I139.

27. Chawla NV, Davis DA. Bringing big data to personalized healthcare: a patient-centered framework. J Gen Intern Med. 2013;28 (Suppl 3):S660-S665.

28. Grossglauser M, Saner H. Data-driven healthcare: from patterns to actions. Eur J Prev Cardiol. 2014;21(2 Suppl):14-17.

29. Issa NT, Byers SW, Dakshanamurthy S. Big data: the next frontier for innovation in therapeutics and healthcare. Expert Rev Clin Pharmacol. 2014;7(3):293-298.

30. Sewitch MJ, Leffondre K, Dobkin PL. Clustering patients according to health perceptions: relationships to psychosocial characteristics and medication nonadherence. J Psychosom Res. 2004;56(3):323-332.

31. Guthrie E, Creed F, Fernandes L, et al. Cluster analysis of symptoms and health seeking behaviour differentiates subgroups of patients with severe irritable bowel syndrome. Gut. 2003;52(11):1616-1622.

32. Hopfield J, Linden RM, Tevelow BJ. Getting patients to take their medicine. McKinsey Quart. 2006;4(1-2):14-15.
Journal of Multidisciplinary Healthcare

\section{Publish your work in this journal}

The Journal of Multidisciplinary Healthcare is an international, peerreviewed open-access journal that aims to represent and publish research in healthcare areas delivered by practitioners of different disciplines. This includes studies and reviews conducted by multidisciplinary teams as well as research which evaluates the results or conduct of such teams or health-

\section{Dovepress}

care processes in general. The journal covers a wide range of areas and welcomes submissions from practitioners at all levels, from all over the world The manuscript management system is completely online and includes a very quick and fair peer-review system. Visit http://www.dovepress.com/ testimonials.php to read real quotes from published authors. 